$28 S$ and $16 S$ RNA with the same base composition as $28 S$ and $16 S$ ribosomal RNA. Kinetic analysis strongly supports the notion that the $50 S$ and $30 S$ nuclear particles are indeed precursors of the large and small ribosome sub-units; the kinetic data also show that in the cytoplasm the pool of ribosomal sub-units is in equilibrium with $74 S$ ribosomes and polysomes.

Pulse-chase labelling experiments indicate that the majority of ribosome sub-units found in the cytoplasm are not newly synthesized. This implies that $74 \mathrm{~S}$ ribosomes dissociate into sub-units at some stage in protein synthesis. Joklick and Becker (1965) and Bishop (1966) reached the same conclusion.

Surprisingly, Vaughan et al. think it unlikely that ribosomes occur in vivo in HeLa cell nuclei. Several other groups have reported the isolation of nuclear ribosomes from other cell types and if they do not occur in HeLa cell nuclei the implication must be that ribosomal proteins are made in the cytoplasm. When and how ribosomal proteins are made and associate with ribosomal RNA romains a mystery. However, the attractive hypothesis that ribosomal RNA before methylation acts as a messenger for the synthesis of ribosomal protein has recently been eliminated by Sypherd (J. Mol. Biol., 24, 329; 1967) and Manor and Haselkorn (ibid., p. 269); they have shown that the apparent messenger activity of ribosomal RNA is due to contamination with $m \mathrm{RNA}$.

\section{Sub-units and Activity}

\section{from a Correspondent in Molecular Biology}

IT has become apparent that the aggregation state of an cnzyme made up of several sub-units is a major factor in controlling its activity. In an article in J. Biol. Chem. (242, 1705; 1967) Frieden and Coleman describe new findings on the relation between sub-unit association and activity in the enzyme glutamate dehydrogenase. This is a particularly interesting enzyme because of the great diversity of the substrates on which it will act and the number of activators and inhibitors which have been discovered. The new work examines the properties of the enzyme as a function of concentration, which over the appropriate range determines its aggregation state in terms of a monomeroligomer association equilibrium. It is established that the inhibitor nucleotides, GTP and GDP, bind more strongly to the monomer than to the polymer.

In terms of the allosteric scheme of Monod and others, a sigmoidal (co-operative) binding curve requires that there should be two states of the protein, which differ in their affinity for the ligand; in glutamate dehydrogenase these forms are evidently the monomer and the polymer. As the concentration is increased, the formation of the polymer is favoured and the binding curve becomes more co-operative. At low protein. concentrations no appreciable amount of polymer is evidently present, and there is no co-operative binding. $\mathrm{ADP}$, on the other hand, which is an activator, binds more readily to the polymer than to the monomer, and $\mathrm{NADH}$ is thought to bchave similarly. The kinetic consequences of this situation have been examined, taking advantage of a chemically modified (acetylated) form of the enzyme, which is active but incapable of polymerizing, and can therefore be used to represent monomeric behaviour at high concentrations.
Another new report on the catalytic properties of glycogen phosphorylase $a$ from muscle as a function of aggregation state comes from Metzger et al. (Proc. Nat. Acad. Sci., U.S., 57, 994; 1967). This enzyme exists in a state of equilibrium between dimer and tetramer. Graves and co-workers have already found that the dimeric form has higher activity, and it now appears that only the dimer is capable of binding the substrate, glycogen. This is therefore another case of enzyme activation by a substrate, which has a much greater affinity for the one state of the enzyme than the other.

A study of muscle aldolase by Chan et al. (ibid., p. 1013) has new implications in terms of sub-unit structure. This enzyme appears to contain three sub-units, and Chan et al. have fractionated these. Each is reported to possess one active site, and convincing evidence, based mainly on the counting of spccific cleavage fragments, is offered to show that two of the sub-units are identical. The enzyme therefore has a structure of the type AAB, and appears to represent the first example of this kind of asymmetry. It must be admitted, however, that there has been some conflict over the number of sub-units in this protein. New results of Sine and Hass (J.Amer. Chem. Soc., 89, 1749 ; 1967) strongly support the presence of three sub-units, and also show that a part of the confusion has been created by a seemingly unique instance of specific alkaline hydrolysis of the polypeptide chain at a $p \mathrm{H}$ of only $12 \cdot 5$. The chains are evidently broken in three defined places, with the appearance of three new $\mathrm{N}$-terminal residues, serine, threonine and glycine.

\section{Asking for More}

Trme Ministry of Technology seems to be relaxing its guidelines on grants to research associations. Already it has arranged to give the British Welding Research Association thirty shillings for every pound that the association can raise from its members instead of the usual pound for pound arrangement, and now it has made a tiny concession to the hard pressed Food Manufacturing Industries Research Association. As reported in Nature $(211,561 ; 1966)$ the BFMIRA has had its problems in recent months, culminating in the resignation of its director, Dr C. L. Cutting, and its secretary, Mr D. H. Martin. Although the administrative arrangements at the association scem to have had something to do with its troubles, the root cause was years of impoverishment and quite inadequate support from many of the British food manufacturers.

The association is now to make an appeal to its members for money to start an urgent programme of re-equipment. Included among its needs are an electron microscope, a mass spectrometer, spectrophotometers, an ultracentrifuge and a mobile laboratory. The cost of this is estimated to be in the region of $£ 68,000$, and the ministry is prepared to match with $£ 1$ every $£ 1$ raised by the association up to a total of $£ 25,000$. This rate of grant is only exceptional in that it is being given for a general re-equipment programme rather than for a single piece of equipment. If the research association can raise more than $£ 25,000$ from its members, the additional money would earn the association general purposes grant at the rate of 50 per cent. The new arrangement, unexciting as it is, does supply some encouragement to Dr A. W. Holmes, the new dircctor of the association. 